\title{
Dogs as Therapeutic Partners, Not Therapeutic Tools: Ethical Considerations for AAT in the Correctional Setting
}

\author{
Kimberly Collica-Cox ${ }^{1, *(D)}$ and George J. Day ${ }^{2}$ (D) \\ 1 Criminal Justice and Security, Dyson College of Arts and Sciences, Pace University, New York, NY 10038, USA \\ 2 College of Liberal and Applied Arts, Department of Government, Stephen F. Austin State University, \\ Nacogdoches, TX 75962, USA; daygj@sfasu.edu \\ * Correspondence: kcollicacox@pace.edu; Tel.: +1-212-346-1862
}

check for updates

Citation: Collica-Cox, Kimberly, and George J. Day. 2021. Dogs as

Therapeutic Partners, Not

Therapeutic Tools: Ethical

Considerations for AAT in the

Correctional Setting. Social Sciences 10:

432. https://doi.org/10.3390/

socsci10110432

Academic Editors: Kimberly Spanjol,

Cathryn Lavery and Heath Grant

Received: 18 June 2021

Accepted: 5 November 2021

Published: 10 November 2021

Publisher's Note: MDPI stays neutral with regard to jurisdictional claims in published maps and institutional affiliations.

Copyright: (c) 2021 by the authors. Licensee MDPI, Basel, Switzerland. This article is an open access article distributed under the terms and conditions of the Creative Commons Attribution (CC BY) license (https:/ / creativecommons.org/licenses/by/ $4.0 /)$.

\begin{abstract}
Although the benefits of animal assisted therapy for people are well established, the ethical considerations for the welfare and safety of the non-human animals involved are not. Without an accrediting body responsible for creating and overseeing national standards, therapy animal organizations are forced to create their own guidelines, creating inconsistencies within the field. Based on interviews conducted with therapy teams who have worked with Parenting, Prison \& Pups (PPP), a parenting program provided to incarcerated jailed women that is integrated with the use of animal-assisted therapy (AAT), this article explores the extent of ethics training offered for AAT teams and will examine how agencies and handlers promote and ensure the safety of canine partners, especially in a correctional setting. The research suggests that specific protocols put forth by individual AAT organizations, which can provide for a national model, can afford for the safety and comfortability of canine partners, especially in a corrections environment, but implies that in order to maintain consistency and increase therapy team professionalism, national standards are a necessity. Guidelines are specifically essential for mental health professionals, who lack guidelines from their own accrediting bodies' code of ethics, and may incorporate non-human therapy partners into their work settings, without proper supervision.
\end{abstract}

Keywords: animal-assisted therapy; corrections; programs; parenting; ethics; non-human animal welfare and protection

\section{Introduction}

... the question is not, Can they reason? nor, Can they talk? but, Can they suffer? Why should the law refuse its protection to any sensitive being? ... The time will come when humanity will extend its mantle over everything which breathes ...

Jeremy Bentham (1789)

Therapy animals are being incorporated more frequently in a vast number of therapeutic interventions. There is significant evidence demonstrating the positive effects of AAT in working with adult and juvenile clients therapeutically, improving physical and emotional wellbeing, such as reducing stress, lessening anxiety, bettering mood, improving emotion regulation, mediating post-traumatic stress disorder (PTSD), decreasing depression, lowering blood pressure, reducing heart rate, mitigating feelings of loneliness and isolation, assisting in overcoming trauma and substance abuse, and creating a positive perception of one's overall quality of health, in addition to enhancing communication and reading skills (Dunlap 2010; Esposito et al. 2011; Geist 2011; Hollman et al. 2020; Kelly and Cozzolino 2015; Kunz-Lomelin and Nordberg 2020; Morrison 2007; Seivert et al. 2018; Stetina et al. 2020). AAT has also been related to improvements in self-control and problem-solving skills among both incarcerated men and women (Stetina et al. 2020). Additionally, in-prison dog training 
programs (DTP) and animal-assisted interventions (AAI) have been found to produce positive outcomes similar to AAT programs (Cooke and Farrington 2015; Flynn et al. 2020).

According to the International Association of Human-Animal Interaction Organizations (IAHAIO 2018), AAT is:

"a goal oriented, planned and structured therapeutic intervention directed and/or delivered by health, education and human service professionals. Intervention progress is measured and included in professional documentation. AAT is delivered and/or directed by a formally trained professional with expertise within the scope of the professionals' practice. AAT focuses on enhancing physical, cognitive, behavioral and/or socio-emotional functioning of the particular human recipient". (IAHAIO 2018, p. 5)

Animal-assisted activity (AAA), another effective intervention, is similar to AAT, but it is provided for "motivational, educational and recreational purposes" (IAHAIO 2018, p. 5). Generally, research finds that both human-animal interactions are very effective in assisting with the healing process and although animal interventions have not received as much attention in the mental health literature as warranted, it is as effective as any other reputable or well-known mental health intervention (Nimer and Lundahl 2007).

Therapy dogs are known to increase participation in counseling sessions, particularly with clients who may be introverted, withdrawn, or reserved (Chandler 2001). AAT promotes communication between humans and has been used effectively to work with incarcerated persons who present with psychiatric or developmental disorders, especially incarcerated women who frequently have trauma-based pasts and a history of unhealthy attachments (Collica-Cox and Furst 2019; Jasperson 2010; Koda et al. 2015). Therapy dogs fulfill attachment functions and can help foster trust, acceptance, and a sense of safety (Brazier 2014; Silcox et al. 2014; Zilcha-Mano et al. 2011), which is necessary when working therapeutically with incarcerated populations but can be complicated by the correctional environment. When clients resist disclosure because a space feels uncomfortable, it can hinder the overall efficacy of the intervention. For therapeutic interventions to work effectively in the correctional environment, the space must feel safe for the client to disclose; this is difficult to achieve in a correctional setting when the prospect of ensuring confidentiality is often problematic and difficult to maintain (McClanahan 2014). However, the presence of therapy dogs can mitigate these issues and not only help group participants in a correctional setting to disclose personal information but help them to disclose information earlier, allowing them to maximize the groups' benefits (Collica-Cox and Day).

It is evident that dogs have substantial health benefits for humans, but little research has been conducted on the impact on the dogs themselves (Glenk 2017). Without an accrediting body responsible for creating and overseeing national standards for AAT, the inclusion of animals in therapeutic interventions is either regulated by individual AAT organizations or largely unregulated when incorporated in private work settings. This exploratory study examines therapy dogs working in Parenting, Prison $\mathcal{E}$ Pups (PPP), a parenting course, that is integrated with AAT, for women incarcerated in two jails-the Westchester County Department of Correction (WCDOC) and the Metropolitan Correctional Center (MCC). Based upon interviews with the 11 therapy teams in PPP, this article explores the ethical implications of working alongside dogs safely in a correctional environment and offers a comparison between jail visits and other types of therapy visits (i.e., visits to schools, hospitals, nursing facilities, etc.). Implications suggest that canine partners can be included safely in a correctional environment, but there is an urgent need to create national guidelines to ensure consistency in canine safety and enhance therapy-team professionalism. Moreover, there is an increased interest by mental health professionals to include AAT in their private practice; although safety concerns for their clients are typically addressed through their corresponding accrediting body's code of ethics, the safety concerns for their canine partner are discounted and noticeably absent (Evans and Gray 2012). Hence, there is a concern that therapy dogs may be incorporated into the work setting without proper oversight. 


\section{Literature Review}

When including dogs in one's work, the primary concern should be protecting one's canine partner. While working, a therapy dog could be harmed by a client or could experience significant stress (Evans and Gray 2012). There is concern that dogs can experience burnout and fatigue, especially in institutional settings where reprieve from residents is difficult (Iannuzzi and Rowan 1991; Ng et al. 2014). Stress in dogs can be monitored through tracking cortisol levels or by learning to recognize stress-related behaviors, such as panting, lip licking, yawning, trembling, barking, wining, pacing, circling, withdrawal, etc. (Glenk 2017; Ng et al. 2014). Both are problematic as valid measurements of stress. First, increased cortisol levels may not always signify stress; heightened levels may be due to excitement or working in a new environment ( $\mathrm{Ng}$ et al. 2014; Ng et al. 2014). Second, the recognition of stress-related behavior is subjective and can be based on the handler's level of training, as well as how observant and knowledgeable the handler is about their canine partner (Glenk 2017). Therefore, the level of training for the handler is vital to the therapy dog's wellbeing.

Limited studies have been conducted which examine the possible stress on therapy dogs in their working environments (Gorman 2019; Pearson 2015; Ng et al. 2014). The differences in AAT/AAA programs not only make it an area difficult to study but is problematic when attempting to make comparisons between studies (Glenk 2017). The studies that have been conducted demonstrate few adverse effects for therapy dogs. Therapy dog visits have not been found to lead to overfatigue or lack of motivation (Barstad 2014). For example, while visiting post-surgical children, therapy dog heart rates did not significantly change (Palestrini et al. 2017). Stress levels appear to remain consistent with therapy dogs, demonstrating similar levels at the beginning and end of a visit (Silas et al. 2019). Minor stress may be noticed, but it is considerably lessened with proper instructions for clientele and a well-trained handler (Barstad 2014; Ng et al. 2014).

Cortisol levels can increase for therapy dogs on visit days compared to non-visit days (Haubenhofer and Kirchengast 2006, 2007; King et al. 2011). If a handler is stressed about a visit, however, it makes it more likely that their canine partner will also be stressed (Silas et al. 2019). The predictability or unpredictability of an environment during a visit may impact stress levels ( $\mathrm{Ng}$ et al. 2014). In one study, the handler's stress levels rose significantly before a session and continued to increase during the session; not surprisingly, the canine's levels rose as well (Haubenhofer and Kirchengast 2007). Transportation of the dogs may explain higher cortisol levels, according to d'Angelo et al. (2021), who found higher cortisol levels in AAI dogs after transportation, with significantly decreasing cortisol levels occurring after AAI sessions with incarcerated persons. Additionally, the population a therapy team is servicing can also impact stress levels. Working with children under the age of 12 years can often be overwhelming, loud, and sometimes inappropriate, potentially creating heightened stress for therapy dogs (Marinelli et al. 2009). Nevertheless, such studies on therapy dogs and stress levels have mixed results; other researchers find no differences in cortisol levels on visit days, especially over time (Glenk et al. 2013, 2014; Ng et al. 2014).

Overall, current literature seems to find limited stress for therapy dogs; nevertheless, the handler's role in this process cannot be underestimated. Dogs need to be purposefully integrated into treatment and the handler needs certain competencies in order to integrate dogs effectively and safely; simply placing a dog in a room during a counseling or group session does not qualify as AAT (Wollheim 2014). The handler is responsible for the canine's physical and mental welfare. Handlers need formalized training to be able to detect stressrelated behaviors, in addition to knowing how to manage such behaviors when they occur (Milani 2016; Ng et al. 2015). The recognition of such behavior is based on the handler's level of expertise and their connection with their therapy dog. Unfortunately, handlers may not always properly interpret their canine partner's emotions because humans tend to assess an animal's emotions based on their own emotions (Milani 2016). Hence, transference is a possibility. Without proper training, a handler may not appropriately recognize signs 
of distress in their canine partner (Hatch 2007), and dogs might be forced to participate in a therapy visit when they are stressed, tired, or afraid (Eccles 2020). Just because a handler enjoys therapy work does not mean that their dog feels the same (Wycoff 2014). The handler must also be cautious of the clientele interacting with the therapy dog and the safety of the physical environment to make sure the dog is not purposely or inadvertently harmed (Granger and Kogan 2000). A dog's behavior will ultimately tell the handler if they want to participate in the intervention (Eccles 2020).

The needs of canines, who have their own thoughts, feelings, and rights, require full consideration before, during, and after integration into any therapeutic intervention (Wollheim 2014). This work should provide the therapy dog with benefits (Hatch 2007; $\mathrm{Ng}$ et al. 2015), and there is a concern that non-human animals may be placed in unpleasant situations with an inability to retreat (Serpell et al. 2000). Without proper handler training, such relationships can be exploitive for the non-human animal considering the significant power differential (Zamir 2006).

Not all dogs are appropriate for therapy work, creating the need for a certification process to ensure a dog's suitability as a therapy animal. Dogs engaged in AAT should also periodically be reevaluated in case their suitability changes as the dog ages. A dog may make an excellent companion but not necessarily make a great therapy partner. The dog's role in programs, along with their backgrounds, age, diet, and physical health, should be considered when selecting dogs for AAT programs (MacNamara et al. 2015; Ng et al. 2015). Therapy dogs should be in good health, enjoy people, be able to remain calm in unfamiliar places with unfamiliar people, and feel comfortable with potential clients touching them, kissing them, hugging them, or as in the case with children, possibly touching them inappropriately (i.e., grabbing their tail) (Glenk 2017). Handlers need proper training to recognize the signs of stress or discomfort in their dog and know how to properly handle such situations quickly and efficaciously (Glenk 2017). Therapy dogs must possess certain personality characteristics (i.e., no sensitivity to touch, well-disciplined, calm, etc.), otherwise they could pose a danger to the client; it is important to remember that as dogs age, their tolerance changes (Winkle et al. 2020), which is why the issue of recertification is just as important as initial certification. However, as Winkle et al. (2020) note, there are problems associated with agency certification. Since agencies have a financial or reputational interest in the dogs they certify, there is often a conflict of interest in safeguarding the welfare of the animals and the clients they serve. Further conflicts arise when the same agency providing the training/education for the team also provides the evaluation to "certify" the team (Winkle et al. 2020). These agencies have a vested interest in passing teams who have completed their training program, creating a lack of objectivity in the process. There also appears to be confusion in the field between the terms certification and registration, whereas therapy dog organizations more commonly use the latter. In order for a dog to be certified, potential therapy dogs would require evaluation and approval by a third party; presently, there are no independent certifying or oversight governing bodies for therapy animals (Pet Partners n.d.). Although there are therapy dog organizations that use the term "certification," the more appropriate term, based on this definition, would be registration.

Not only is it necessary to determine if the clients are appropriate for a particular dog's personality, but the physical environment a therapy dog is brought to for work needs to be vetted for safety. Issues such as small spaces, limited water, or high temperatures can create an uncomfortable and stressful working experience for a therapy dog (Iannuzzi and Rowan 1991). The length and frequency of visitation should be strongly considered, where some researchers recommend limiting visits to $30 \mathrm{~min}$ to one hour and no more than three visits per week (Iannuzzi and Rowan 1991; Ng et al. 2015).

While the literature on AAT / AAA continues to grow, there is a dearth of information regarding proper team selection, preparation, training, and evaluation (Winkle et al. 2020). A lack of national standards creates inconsistencies in ethical training and practice for therapy teams (Pearson 2015; Winkle et al. 2020), and without professional credentialing, no method exists to ensure the proper and safe inclusion of therapy dogs in practice. There 
continues to be no national body to develop standards and no consensus among individual organizations for certification or recertification (Winkle et al. 2020; Ng et al. 2015). Although standards and competencies exist on the use of AAT, there is no governing body that can offer certification, creating inconsistencies in the way teams are trained and evaluated, as well as in the way they can initially qualify as a therapy team or requalify annually.

Consistency in standards would serve to protect canines, who cannot volunteer for this work, have their own needs, and are not here specifically to serve humans (Taylor et al. 2016; Winkle et al. 2020). Hence, more rigorous standards are vital to protect the welfare of the therapy dog, and handlers need to be advocates for their canine partners. Anyone employing AAT in their work must consider the possible legal and ethical issues (VanFleet et al. 2015). Although individual therapy dog organizations have their own standards, protocols, policies, and requirements, they vary from agency to agency (Ng et al. 2015). Questions arise about the suitability of the handler and canine for this work, such as whether the canine is enjoying their work, when the canine should retire, or how many hours a canine should work per day or week (Pearson 2015).

The handler is not only responsible for the welfare of the therapy dog but the welfare of the client while working with the therapy dog, creating role conflict as they have to split their roles and attention to safeguard both simultaneously (Allen and Colbert 2016). Clients should be asked (i.e., informed consent) if they are interested in working with a therapy dog and be provided with the benefits and risks of working with animals (Shelton et al. 2011); some clients may be fearful of dogs, suffer from allergic reactions, or have cultural beliefs which create reluctancy to work with them (Winkle et al. 2020). Everyone in the setting, including staff, should be informed of an animal's presence (Allen and Colbert 2016). It is recommended that canine partners are continuously observed, and if signs of stress are exhibited, they should be removed from the setting (Allen and Colbert 2016). Therapy dogs should be allowed multiple breaks, particularly if the canine remains with the handler at their place of employment; they should have access to fresh water and have a safe resting spot available, with limited stimuli, especially in an institutional setting.

With a lack of national standards from an accrediting body, handlers and researchers must rely on individual therapy dog organizations or other professionals in the field for guidelines and best practices. The inclusion of canines as therapeutic partners must make the safety of the dog primary, especially in a correctional setting, where the environment can often be unpredictable. Based on interviews conducted with therapy teams who have worked with Parenting, Prison \& Pups (PPP), a parenting program provided to incarcerated women, that is integrated with the use of animal-assisted therapy (AAT), this article explores best practices for the inclusion of therapy dogs in correctional settings and will examine how handlers promote and ensure the safety of their canine partners in two different New York jails.

\section{Methods}

\subsection{Parenting, Prison $\mathcal{E}$ Pups (PPP)}

PPP is modeled after the evidence-based Parenting Inside-Out (PIO) curriculum that previous research has found to dramatically decrease depression, lower substance abuse, increase parental participation, enhance parenting skills, reduce parental stress and parental depression, increase parent-child interactions and interactions with the child's caregiver, and reduce recidivism for participants (Eddy et al. 2013; PIO n.d.). PIO, a cognitivebehavioral parent management program, was reviewed by the Substance Abuse and Mental Health Services Administration and is included on the national registry of evidencebased programs and practices (PIO n.d.). When PIO is integrated with AAT (i.e., the PPP program), research finds statistically significant lower rates of parental stress and anxiety and higher rates of self-esteem and parental knowledge; the integration of therapy dogs also appears to increase communication, trust, and connectedness between group members (K.C-C and G.J.D. Forthcoming). 
The PPP program takes place at two different jails; the Westchester County Department of Correction (WCDOC), the second-largest county jail in New York State, located 20 min north of Manhattan, and the Metropolitan Correctional Center (MCC), a federal holding facility managed by the Bureau of Prisons in Lower Manhattan in New York City. Each class includes two therapy teams (human and non-human animal), three to four Pace students as teaching assistants, and the PPP instructor. At least one of the therapy teams present during each class is a licensed mental health worker and the instructor/director, a human service provider, has 24 years of experience providing social services and programming to incarcerated men and women. Women participants of PPP can engage with the therapy dogs before, during, and after class. The dogs are integrated into the lessons and serve as examples to build upon more difficult concepts such as problem-solving or communication skills; they also serve as a source of emotional support for women while discussing difficult topics (i.e., their separation from their children, past abuse, etc.). There are two therapy dogs per session and parenting classes are offered to women at both jails twice per week, two hours per class, for approximately two months, for a total of 14 classes. Each session is longer than a typical therapy dog visit (i.e., two hours versus one hour). The dogs are not fully engaged for the entire two hours, however, often resting (i.e., laying down) while the instructor is teaching and/or the group is processing. PPP examines whether incarcerated women participating in parenting courses with AAT experience lower levels of stress, anxiety, and depression, in addition to increased self-esteem and parenting skills knowledge, compared to women in parenting programs not utilizing AAT. Previous research on PPP found differences between mothers who completed a parenting course with AAT (i.e., Parenting, Prison \& Pups), compared to those who completed the same course without AAT; statistically significant lower rates of parental stress and anxiety, in addition to higher rates of self-esteem and parental knowledge were found among the AAT group (see K.C-C and G.J.D. Forthcoming).

\subsection{Sample}

The study's sample included all therapy teams who worked for PPP at either WCDOC or MCC. Of the twelve people who worked for PPP since its inception in 2017, 11 members were interviewed, yielding a $92 \%$ response rate. The 12 th team was not interviewed since they only participated in three jail visits. The 11 other teams completed at least one full cycle of PPP, consisting of eight weeks. The sample was comprised of two males and nine females (see Table 1). The average time working as a therapy team with their canine partner (not necessarily with PPP) was three years. The majority of respondents had a master's degree $(n=6 ; 55 \%)$; two had a high school diploma $(18 \%)$; one each $(9 \%)$ had an associate's degree, bachelor's degree, or a juris doctorate. Five of those at the master's level possessed a Master of Social Work, and one earned a master's degree in science education. At the bachelor's level, one member had a dual major in nursing and psychology. Teams worked in various settings with their canine partner such as hospitals, rehabilitation centers, schools, military bases, nursing homes, company events, adolescent facilities, libraries, and private counseling practices. Teams have serviced elementary school children, middle schoolers, high school and college-aged students, cadets, veterans, those with substance abuse issues, those with mental health diagnoses, or those presenting with physical or cognitive impairments. Each team was in good standing with their respective therapy dog organization at the time of the interview (i.e., Hudson Valley Paws For A Cause or The Good Dog Foundation). Dogs comprised all different breeds, including three Labradors, two Labrador mixes, and one Labradoodle, Labradoodle mix, St. Bernard, Chihuahua, German Shepperd, and Coton de Tulear. On average, these dogs were introduced to their handler at eight months, with the youngest adopted at two months and the oldest adopted at two years. All handlers were aware of their dog's history prior to adoption; five dogs were purchased from a breeder, two were adopted from Guiding Eyes for the Blind (i.e., an organization that trains dogs as service animals for the other-abled) as career changing dogs, and the remaining four were rescues (i.e., adopted from animal shelters and rescue 
groups, or abandoned and in need of housing). All handlers believed in the use of positive reinforcements for training, with all utilizing food reward $(n=6)$, a mixture of food and praise $(n=3)$, a mixture of food and toy reward $(n=1)$, or praise $(n=1)$. None of the handlers used punishment or adverse reinforcement for training.

Table 1. Dog-Handler Team Descriptions.

\begin{tabular}{|c|c|c|c|c|c|c|c|c|}
\hline Team & $\begin{array}{l}\text { Handler's } \\
\text { Gender }\end{array}$ & $\begin{array}{c}\text { Time w/ } \\
\text { Current Dog }\end{array}$ & $\begin{array}{c}\text { Handler's AAT } \\
\text { Experience }\end{array}$ & Handler Education & $\begin{array}{l}\text { Dog's } \\
\text { Gender }\end{array}$ & Dog's Breed & $\begin{array}{l}\text { Dog's } \\
\text { Age }\end{array}$ & $\begin{array}{l}\text { Dog } \\
\text { Source }\end{array}$ \\
\hline 1 & male & 5 years & none & MA_-Social Work & male & Black Lab & 8 years & $\begin{array}{c}\text { Guiding } \\
\text { Eyes }\end{array}$ \\
\hline 2 & male & 4 years & none & $\begin{array}{l}\text { MA-Science } \\
\text { Education }\end{array}$ & female & English lab & 4 years & breeder \\
\hline 3 & female & 3 years & none & J.D. & male & Yellow lab & 8 years & breeder \\
\hline 4 & female & 1.6 years & none & $\begin{array}{l}\text { BA-Psychology; } \\
\text { BS-Nursing }\end{array}$ & female & St. Bernard & 3 years & adopted \\
\hline 5 & female & 3 years & none & MA-Social Work & female & Chihuahua & 5 years & rescue \\
\hline 6 & female & 1 year & none & High school & female & $\begin{array}{l}\text { Chocolate } \\
\text { lab/Shar-pei, }\end{array}$ & 5 years & rescue \\
\hline 7 & female & 4.5 years & none & MA_-Social Work & male & Labradoodle & 5 years & breeder \\
\hline 8 & female & 4 years & 3 years & Hish school & male & German Shepperd & 6 years & $\begin{array}{c}\text { Guiding } \\
\text { Eyes }\end{array}$ \\
\hline 9 & female & 4 years & 19 years & MA-Social Work & female & Labradoodle mix & 6 years & rescue \\
\hline 10 & female & 4 years & 12 years & AA-Business & female & Cotton de Tular & 5 years & rescue \\
\hline 11 & female & 5 years & none & MA-Social Work & male & Labradoodle & 6 years & breeder \\
\hline
\end{tabular}

\subsection{Data Collection and Analysis}

The current study is exploratory in scope and utilized a qualitative design to allow for an in-depth examination of each team's experiences and to identify common themes in those experiences. Each team was interviewed by one of the researchers via phone or Zoom utilizing a semi-structured interview schedule consisting primarily of open-ended items. On average, interviews took approximately $46 \mathrm{~min}$, with the shortest interview lasting $25 \mathrm{~min}$ and the longest lasting $70 \mathrm{~min}$. The interview schedule consisted of four distinct categories which included the handler and therapy dog's profile, as well as appropriateness for therapy dog work (i.e., level of education, years working as a therapy team, settings visited as a therapy team, and their dog's age, breed, adoption history and personality characteristics); their experience with AAT work (i.e., why they became involved with AAT, how they knew their dog would be interested in this work, why they were interested in PPP, etc.); how they ensured their dog's safety (i.e., how they determined if a site is safe, how they provided for the safety of their dog, the signs they looked for to determine if their dog was stressed during a therapy visit, if they ever stopped visiting a site for safety concerns, etc.); their initial training, requalification and whether they were knowledgeable about the ethical inclusion of dogs in AAT (i.e., their AAT training, whether they received ethical training in regard to working with their dogs in AAT, their recertification process, etc.); and their specific experiences working in a jail setting (i.e., if there was anything at the jail that caused concern for their canine partner, how a jail visit differed from a typical therapy visit, if they enjoyed their work in PPP, if their dog enjoyed working in PPP, if they prepared differently for a jail visit; etc.).

All questions were read to participants. Responses were recorded in written format and transcribed the same day; quotes provided are verbatim transcriptions. One researcher conducted the interviews to maintain consistency in the interviewing process. Responses were then analyzed using content and thematic analyses and coded utilizing a framework analysis, managing data by case and theme, to identify commonalities in the participants answers (Glaser and Strauss 1967; Miles and Huberman 1994). A codebook was developed, providing definitions for concepts, identifying themes emerged, and succeeding concepts categorized (Glaser and Strauss 1967). Coding was a continuous process with several response categories emerging, including therapy dog appropriateness; dog safety; training, requalification, and ethics; and handler experience specific to the jails and PPP. Initial 
themes emerged unique to each category and were reorganized during multiple transcription readings. Individual themes in each category are identified in the study's results. Four themes emerged from the data, consisting of the special bonds which exist between canines and humans; confidence in the recognition and handling of stressful situations; differences in qualifying or requalifying as a therapy team; and the feasibility for the wellbeing and enjoyment of the canine partner in a correctional setting. Subsequent analyses detected similarities and differences in responses to the interview items. Representative quotes were selected to describe categories and themes within categories.

\section{Results}

\subsection{AAT, PPP E Therapy Dog Appropriateness}

Overall, teams were committed to their work in AAT and PPP. Therapy teams were asked why they decided to pursue AAT. The responses varied: two thought their dog was a natural helper, two felt strongly that the human-animal bond helps with engagement, two believed in the healing power of dogs, one was asked by an employer to get trained, one was intrigued after seeing how her patients reacted to her dog when they came to her home for individual counseling, one had prior experience in equine therapy, and one read about it and was instantly interested in pursuing it. One theme consistent in the data was that all handlers recognized the special relationship that humans and animals share; teams felt that AAT was clearly advantageous, especially for clinical engagement:

Clinically, I see that it helps with engagement. It helps us to understand the impediments to bonding in human relationships by watching the way the clients can or cannot interact with the dog.

They witnessed the impactful effects of AAT on others:

My whole life I saw and I felt that dogs were healing. Who doesn't want to pet a dog? I saw dogs at different functions and then my daughter had surgery. She was next to the Ronald McDonald House and I saw the dogs go in there to heal the children. When I got [my dog], I thought she had the perfect sensibilities for it.

Another team member just loved the idea:

I was involved in equine therapy and I was talking with someone who told me about dog assisted therapy. I love dogs and I love therapy. I was like, you're kidding! It was the perfect match.

Most teams decided to apply to PPP because they were approached by someone at their respective therapy dog organization who thought they would be a good fit for the program $(n=5)$; four others felt it was a wonderful opportunity; one had experience working in corrections; and one had a formerly incarcerated family member and was interested in working with this population. One of the licensed clinical social workers (LCSW) always wanted to work with this population:

Everything about it interested me. I always worked with underserved populations, especially during the AIDS crisis. The jail population was always an area I wanted to get involved with but I never could access it. Second, I liked working with women. Third, I liked the parenting piece and I had firsthand experience. When you put together all those pieces, it was perfect.

One of the LCSWs who had corrections experience thought it would be a great opportunity:

I was so excited. I have been a forensic social worker for 15 years. And to think about innovative programs and ways to do things better in trauma work both inside and outside the facility was exciting. I was so grateful to engage in therapeutic work with my dog because I never did it before.

Team members were asked why they thought their dog would enjoy therapy work; six felt their dog had the right temperament for this work, two said their dog was previously trained as a service dog, one believed people would gravitate toward her dog who was 
nice and small, and the last member honestly believed that any dog, with effort, could be trained for therapy work. As one team member mentioned, receiving a career changing service dog is a perfect partner for therapy work:

It was pretty easy-he was a release dog from Guiding Eyes for the Blind. They have a subset of dogs who are fully trained and just about to be reassigned but for some reason there is an issue in one area; if that issue cannot be remediated, they are placed for adoption.

Teams were asked what characteristics or traits make a good therapy dog and four cited temperament, three said the dog had to be really calm, one said dogs need to read energy well, one said dogs have to have a need to please the handler, and another said that dogs have to be comfortable with being touched all over. One handler spoke about his dog as possessing these traits:

The most important character is temperament and secondly is intelligence. They have to be well trained. They have to be able to concentrate. They have to be able to work with other dogs there. He's a working dog and he knows the difference between play and work as soon as I take out the bandana.

Teams felt confident in recognizing signs which would denote whether their dog was enjoying their work. Eight team members relied on visual signs (i.e., wagging tail, ear position, walking around effortlessly, appearing relaxed, etc.), and the remainder said they could tell their dog was enjoying their work if the dog was very affectionate, engaged, or would show their tummy. As one member explained:

[It's] their body language. Are they happily engaging and looking around to see who wants to engage with them? Are they comfortable and just grabbing a snooze or are they stress napping? You have to look at their body language to see if they are reacting to sound in a negative way... If the ladies called him over and he thought about it but decided against it and turned back toward the handler, that is a sign. Do they have to be coerced to engage? And it might not be about the women but about the environment. You want loose, happy, body language.

\subsection{Ensuring Dog Safety}

A second theme that emerged from this data was the recognition of, and ability to handle, stressful situations. In order for one to be an advocate for their canine partner, they must be adept at recognizing signs of stress or displeasure. Teams discussed traits that would make a dog inappropriate for therapy work, such as being too hyper $(n=4)$, aggressive $(n=3)$, disobedient $(n=1)$, nervous $(n=1)$, anxious $(n=1)$, and not being fond of new people $(n=1)$. One handler discussed traits that should automatically disqualify a canine from therapy work:

Any dog which is aggressive toward other dogs. Any kind of aggression is a rule out immediately. You also need to look at the dog's ability to be trained, bond, relate to others, both adults and children, and their ability to discriminate between work and play.

Teams felt confident in recognizing if their dog was not enjoying their work. Seven team members said their dog would disengage or turn away from clients, two said their dog would lay under their chair or on their feet, one said her dog would not engage without treats, and one said if her dog was panting or pulling it was a clear sign that they were unhappy:

If I have to use a lot of treats to encourage her to engage, she is not loving it. This is why she likes the prison. The room is open and she can go from person to person. She can be mobile and she gets a lot of attention. She also loved reading to the kids. If she is not enjoying it, she will get closer to me.

She will walk away, pant or stay constantly on me. If she's done, she will come over and nudge me. We went to a school of 5th and 6th graders and they were all over her. She was tolerant of it but after a while she was done. She came over and nudged me. 
One member, who is also a trainer, said it is important to remember that dog language is not universal:

It is not always a tail wagging. Tail wagging doesn't necessarily mean a dog is happy. But if he's wagging and looking to engage, then he's happy. Body language is not universal. Dogs express themselves in different ways. In the training, they learn to read their dogs and it helps them to better bond with their dog. You will learn if your dog's tail wag is happiness or uncertainty.

Nine of the 11 teams said they had visited sites where their dog exhibited one of these signs. Three attributed their dog's displeasure to screaming/noisy clients, three said it was mishandling by a client, and one each attributed it to disliking wheelchairs, nursing facilities, or very large spaces. When these incidents occurred, teams knew what to do to protect their dogs (i.e., move them, be stricter with instructions for interacting with their dog, leave, take a break, etc.):

Yes at the ACS (Administration for Children Services) foster place. The foster kids came in screaming and they were touching him too much. It was noisy and chaotic. I didn't go back. I didn't leave because it was a place where you had to be escorted in and out but I pulled him over to me and held him. I sat on the floor with him. I put my arm around him and I was very strict about them touching him.

At this school some of the kids were touching or pulling her tail and poking her. I just moved her and we left. I also visited a day treatment program and one of the young adults was getting anxious. He was screaming, yelling and clapping. She did not exhibit signs of stress but I thought it was too much. I just moved her to a different area.

One handler's dog was overwhelmed by children during a therapy visit but she took control of the situation to make sure her dog and the children had a beneficial visit:

Yes when he was cornered by all of those children. It was the only time. I got in-between him and the children and I gave them instructions on how to touch him and how not to touch to him. I didn't want him to be afraid and I didn't want the children to be afraid. I just moved him away and showed them what to do. It was a positive experience and we always want to be a positive experience.

In some cases, a team member would notice that their dog did not enjoy visiting a particular place or a specific population and the team member would stop working with their canine partners in those environments:

When we have visited nursing homes she is not as engaged. No one else would notice it but that's why you have to be an advocate for your dog. She would just stand there and let them pet her but she wasn't really enjoying it, so we just don't go.

He did not really enjoy visiting with the adults with autism. He is ok with groups and he is ok with unpredictable noises, but depending on the situation, he doesn't like the two combined. There were always five to a dozen people and they were unpredictable. He tolerated it but he didn't enjoy it and I didn't think it was a good fit long term. We went five or six times to see if he would become more acclimated but it was just not something he enjoyed, so we stopped going.

All 11 team members said they constantly, continuously, and consistently monitored their dog's behavior during a therapy visit to make sure they were safe and felt comfortable:

It was non-stop. I am way too introspective for my own good, so I was constantly evaluating the setting and her in that setting. Since the focus was on her, there was no time to think about myself.

[I was watching her] the whole time. You have to pay attention to the signs of stress- it is part of the training. We even learned that if we feel they are stressed, we should just touch them and that can help to calm them.

Teams were asked how they determined whether the site and the clientele were safe for their canine partners. Eight of the teams said they relied on their respective therapy 
dog organization to vet a site before they went. These handlers felt their organization did a great job of vetting these places to ensure their safety and the safety of their canine partner. Other handlers tended to look for signs of stress $(n=1)$, cleanliness $(n=1)$, or the behavior of the clientele $(n=1)$ to determine if a site was safe:

I don't go in unless the site is approved by [name of therapy dog organization]. It is vetted before we are allowed to volunteer there. They certify the site. There is a whole checklist of what they do to certify the setting.

They [name of therapy dog organization] are wonderful and make volunteering so easy. They scope out everything first and make sure it's safe. They ensure that you have insurance and the clientele is safe. They do their due diligence before we go.

Teams were very cognizant about the number of therapy visits they allowed for their dog. Although many admitted that the number could sometimes be dependent on the type of visit, the average number was three per week, ranging from one visit to five visits weekly:

Not more than 2-3 times per week but it really depends on the type of visit. If it was the nursing home, probably three times. If it was the jail, probably two.

\subsection{Training, Recertification $\mathcal{E}$ Ethics}

Qualifying or requalifying as a team differed depending on the therapy dog organization, highlighting a third theme, inconsistencies in the field. In order to prepare for their visits for PPP, all therapy teams had to qualify under one of the dog-assisted therapy organizations with which they were affiliated. Only two teams took the test for becoming a therapy team without undergoing a therapy team training; the remaining teams went through a training that was either four, six, or eight weeks, for approximately one hour per week. Three of the teams were also certified as crisis response teams through the Red Cross. Dogs were typically tested at the end of the training and then shadowed on their first few therapy team visits before they were officially registered as a therapy team. Requalification varies, with one agency requiring approval through an insurance company and one where the team is approved through the respective therapy dog organization. Both require an assessment of the dog's health and medical records. One required a certain number of therapy visits per year, while the other required an in-person visit with an evaluator for the dog to be retested on their ability to follow commands. One team explained the yearly requalification process:

We are evaluated yearly. You have the vet stuff, being up-to-date with shots and then you pay a fee and you to go to a place to meet with a trainer and they have to do all of the commands like sit, stay, and down. They have to walk loosely on a leash. They have to be able to walk by things on the ground like food. The trainer will make loud noises and they have to be able to withstand that.

In addition to their training to become a therapy team, all teams went through two trainings for PPP. One three-hour training was held with the PPP director to acquaint teams with their roles, responsibilities, the curriculum, and the jail setting. Another three-hour training, which reviewed safety and security, was held at each respective jail for teams to receive their volunteer identification status:

[The PPP director was] very clear about the program, the syllabus, the nature of the population, what the setting was like and the requirements for entering and leaving. We also had all of those meetings and I had an orientation at the jail and one with [the director] in NYC.

All handlers felt they were properly prepared and trained for the jail setting:

I felt overprepared but in a good way. [The] training was so comprehensive about the course. [There was] a lot of information on the content about positive communication, improving relationships and the different parenting styles. Information is power and before I didn't really know what was happening so I found this to be very helpful and fascinating. The jail orientation [at the WCDOC] was great. The man who ran it was 
superb, interactive and engaging. He gave us information on any possible situation that could happen. I loved that. I would not want to go in and be in a situation where no one told me that it could possibly happen. I felt the jail was very flexible and so responsive.

Two of the handlers said that even though they felt prepared, one can never be totally prepared to work in an unfamiliar setting such as a jail:

I was as prepared as I could be but I don't think you are ever totally prepared to go in until you go in.

After the third year, teams were allowed to visit the facility before the start of classes to see how their dog managed in the jail environment (i.e., managing the long corridors, the noises, the smells, etc.). This change was proposed and approved when three new therapy teams began during the fourth year of PPP.

Interestingly, only five of the 11 therapy teams stated that they received ethical training regarding the inclusion of their dog in AAT from their respective therapy dog organization. Both therapy dog organization's manuals, however, clearly address ethics and engaging one's dog in therapy work. In fact, one organization labeled this section as Code of Ethics. Two members vividly recalled this portion of the training:

Yes they were very clear about the requirements and understanding the dog's mood. You have to know what signs to look for like excessive licking, whining or looking for the door. The [name of organization] had a checklist to review to make sure the dog was comfortable.

[The name of organization] always told us to look for signs of fear and anxiety and do what's best for our dog at any cost. When she started talking about this, my ears perked up because of my background. If we feel any situation is stressful, we are told to exit the facility. If the dog is not comfortable, you shouldn't be there.

Others said they did not recall learning information concerning the ethical inclusion of their dog in AAT. Upon further probing, all team members learned about the ethics of AAT, but if it was not formally labeled or categorized by the trainer, they did not identify it as ethical training.

\subsection{The Jail Specifics of AAT}

The rules and procedures for the safety of the therapy teams are typically enacted by the animal assisted therapy organization of affiliation, but PPP added to these safety protocols for the corrections setting. When visiting the jail, teams were escorted by an officer or would use hallways that were not frequented by the incarcerated to minimize safety concerns. Participants in the program were approved by jail staff and the PPP Director. Anyone with a history of behaving violently in the facility while incarcerated would not be considered appropriate. Dogs were always kept on a leash close to their handlers while walking into and throughout the facility, and staff were informed before dogs entered a housing unit or an elevator to assess comfortability. If a staff member expressed discomfort, teams would not proceed until they could maintain a safe distance between them and the staff member. The same applied to those who were incarcerated but non-PPP participants who expressed discomfort about being close to the dogs.

In order to determine if there were specific issues related to therapy dogs working in a jail setting, teams were asked if there was anything at the jail that ever caused them concern for their dog. The majority $(n=7)$ stated they never had any concerns, but four expressed initial concerns. The concerns included food on the floor and/or loud noises $(n=2)$, using the elevator $(n=1)$, and being in a large space for graduation $(n=1)$. When concerns were expressed to the respective facilities, the majority were rectified. In one case, one of the therapy dogs licked coffee grounds off of the facility floor when the teams arrived in the classroom. The director spoke with the warden and the room was mopped and cleaned directly before the team's arrival and was never again an issue:

The only time was when there were coffee grounds on the floor and he licked them. He was sick later but I never knew if it was because of that. The women mopped the floor 
every time before we came in after that. But I never saw him show any signs of stress. I know him so well and he would show signs of panting, hiding and shaking [if he was stressed]. He is so excited to be there. He loves the staff and the women equally-they have no learned prejudice. He sees them all as wonderful.

In another case, one of the dogs was not comfortable utilizing the elevator. Again, the warden made arrangements for the dog to gain access to the classroom without having to utilize the elevator, rectifying this issue:

Yes the elevator. When we first went to the jail, we used a service elevator. I have been inside a regular elevator with her but they don't move as jerkily. She was petrified. The facility was so nice - they allowed us to walk outside to one of the other entrances so we didn't have to take the elevator. That made a huge difference.

The other two issues could not be rectified, and in fact, neither had been reported to the director. A large space is needed for graduation but one of the handlers felt this made her dog uncomfortable. She said she kept her dog close to her during the graduation, and this appeared to help her canine partner's anxiety. This team only participated in one year of PPP. Had she participated another year and expressed this concern, she would not have been asked to attend graduation:

During the graduation, we were in a big room that was very sterile. I think she was really unhappy. It wasn't the amount of people because she has done reading programs with 20 kids petting her but I think the room was too large. There was like an echo. I kept her next to me and hand on her the whole time.

The last issue regarding noise was unavoidable. Facilities can be very noisy (i.e., alarms, yelling, etc.). As one of the trainers (who also served as a team member) noted, it is important that dogs are able to recover from such noises rather quickly. It is difficult, however, to test for this outside of the jail setting:

If something happens, you want a good recovery in like thirty seconds where they don't even remember what happened.... [We had] that one class where we had that guy in solitary who was banging on the door. It was pretty consistent for those two hours we were there. If there is one outburst, the dog can easily recover but with the case of the guy banging on the door, it becomes a chaotic environment sound wise. I choose dogs carefully that I thought would be ok. Most of the teams were also trained in crisis response where we test for unusual situations and sounds. We don't usually test for that level of noise in the regular therapy class.

One team member discussed how his dog easily managed loud noises making him a great fit for the jail:

[My dog] was used to working in institutional settings. As long as I am with him, he feels secure. I never have him off leash. He relates well. He is a secure animal. My wife takes him to a nursing home and when the alarms and sirens go off, he acts like he doesn't even hear it. In the training, they will walk up behind you and drop a stack of books to see how the dog reacts to the noise and he doesn't react at all. He doesn't react to wheelchairs or people wearing masks. The training really tries to mimic real world settings.

A few teams expressed initial nervousness because they had never been in a correctional setting, but after their first visit, they were put at ease:

On day one I was nervous but there were a lot of protocols and procedures to promote safety. The waiting could be long but I don't think there was anything that could be done because we had to go through the process. I don't think they could have done anything better. I never felt like they needed to do anything more to make me or her feel safe.

At first it was safety. It was a different venue than we were used to or have ever done. But my concern was laid to rest after going there. Physically I felt safe. It was clean. When we went there, everything felt fine and since it was done before, there was no hesitation on my part. 
Almost all teams $(n=10)$ recognized that a jail visit differed from a typical therapy visit because the length of the visit was longer $(n=3$; i.e., two hours versus one hour), security procedures were more intense $(n=3$; i.e., metal detectors), their mobility was limited ( $n=2$; i.e., they could not leave the classroom until the session was over), they needed to be more cognizant of the type of personal information they would share $(n=1$; i.e., personal information they might share during other visits, such as the town they might reside, could not be shared in this setting), they were not the one in charge of the session as they normally would be ( $n=1$; i.e., they are usually the ones in charge of their visit), and there were additional dogs $(n=1$; i.e., during most therapy visits, they are the only team present):

There were two dogs and two trainers. Usually there is just me and [my dog].

The biggest difference was being in one room rather than moving from room to room.

Just the security. You have go through the metal detectors and be mindful of dress.

I'm the one that's usually running the session. It's usually unstructured and this was structured. I wasn't the leader. I have been in groups before with my dog but I was leading the session.

One member expanded on being more cautious with the disclosure of personal information:

It is a typical visit but I take precautions with what I say. I can be more open with what I am talking about when I visit a nursing home for example. I can talk to the patients about my grandchildren. The jail orientation made it clear that we should not share personal information. I could share that I had grandchildren but nothing too personal about them. So I was little more conscious with what I was saying. I was conscious of everything because I knew this program was a big part of their day and I wanted to do right by them.

Another member discussed the longevity of the jail visit:

It was longer. It was usually $2 \frac{1}{2}$ hours by the time we went in and out and sometimes it might be three. Typical visits are only an hour. You have to see if the dog can handle that duration. There are also different noises and activities that will be encountered. We expected different things from these dogs, a higher standard.

Only three team members said they prepared differently for a jail visit when compared to a typical therapy visit by dressing down $(n=1)$, bringing water $(n=1)$, or being mindful about the items they were allowed to bring inside with them $(n=1)$. The remainder of the teams $(n=7)$ said they did not do anything differently to prepare for a therapy visit to the jail:

No, we have the same routine. I tell her that we are going to work. She has a special work leash. I put it on her and she does react differently when we get out of the car at the jail. She is less excited when we visit the nursing home. I think is she excited about the jail because we have that long walk outside where she can sniff and it amps her up.

No I approach any therapy visit by making sure she had exercise for a few hours beforehand and also a walk before. There would be no difference in my approach.

Any differences seemed to be more related to the handler than to the canine:

I had to dress down, where I might dress up for other places. I am freer to wear what I want when I visit other places. Here I would not wear makeup or jewelry. I would wear my baggy pants. In a way it was a nice break from having to dress up.

Just that I had to buy a bra without wires.

I had to prepare in terms of what I packed. I had to pack a clear water container and a clear bag with [my dog's] treats.

To assess whether their canine partners enjoyed their visit at the jail, handlers were asked to assess their canine's behavior as they arrived at the facility, during their visit in 
the facility, and their dog's demeanor following a visit, highlighting a fourth theme in the data-the canine partner's wellbeing in, and enjoyment of, the correctional setting. Ten of the 11 teams said their dog really enjoyed the visit; one handler was unsure if her dog loved visiting the facility because he appeared more subdued when compared to a typical visit; however, he did not exhibit any specific signs of stress. The remainder of the teams said they could tell their dogs enjoyed visiting the jail because their dog was very engaged $(n=5)$, very excited $(n=4)$, and loved all of the attention $(n=1)$ :

He loved it. He got all the attention and everyone was fussing over him.

She would walk around and engage everyone and she was excited when Wednesday (the day of the class) would come.

Yes very much. He always pulled me to go in, although without other signs that does not necessarily mean he likes it. It could be that it was a familiar place. But his body language, when he did that stretch and his willingness to engage showed he enjoyed it. He has a big open mouth, almost smiling. A sparkle in his eye and his tail would wag in a very loose way.

Yes he loved his trips to the jail. He would almost pull my arm right out of the socket when we got to the parking lot trying to get inside. You could see his joyfulness and exuberation. He's so happy and he is doing what happy dogs do, which is wagging his tail.

Most handlers did not notice anything concerning about their dog's behavior as they approached the jail. The majority $(n=6)$ said their dog was interested or excited, exhibited normal behavior $(n=3)$, or was happy $(n=1)$. One handler felt her dog behaved more carefully during a jail visit $(\mathrm{n}=1)$ but only as they went through processing:

People were petting him as soon as he got there, like staff, and he thought, this is great.

There was nothing to make him think this was different than any other visit.

She was excited as soon as I put the red vest on her.

Most handlers did not notice any specific changes with their dogs during the actual visit. They stated their dog was happy $(n=3)$ and engaged $(n=2)$. Three said there were no changes at all. One handler said her dog was anxious on the first visit but fine after the group was initially settled, while another mentioned that her dog appeared to be more subdued when compared to his visits with school children:

Always good and engaged. Everyone reacts differently. If someone was excited to see her, she was excited. If someone was calm, she would sit next to them and be calm.

He loosened up as we got there and as people petted him, he was very content and wanted to be pet more. He would be very engaged.

He was very interested in what was going on.

He was more subdued. He wasn't stressed. When I was going regularly, he was engaged. But when I filled in one time for someone, I don't think he was used to it and he didn't seem as engaged. But when we were coming in and going out, the women were hugging and petting him and he was fine with it.

The majority of teams $(n=9)$ said there was no change in their dog's behavior following the therapy visit compared to their other visits. One handler was not sure. Five of these handlers thought their dogs were tired, but their dogs were always tired after any visit; it was not specific to visiting the jail. Two handlers thought their dog might be a little more tired because the visit was longer when compared to other therapy visits:

There was no difference. He is always the same after each visit. He's not tired. Normal. He was always ready for a nap after being there for a few hours.

I think she was more exhausted than after a typical visit because it was longer. 


\subsection{The Handler's Experience}

Handlers were asked about their experience participating in PPP. Except for one handler, this was everyone's first time working in a correctional setting. Despite this, all of the handlers enjoyed their experience, felt safe, and believed the program was beneficial. Some of the handlers spoke about the value of the program, with women sharing their experiences openly:

I valued the program and working with women who were mistreated and marginalized. I could see it working each and every week. Even how they might reframe a question when they called home to talk to their family and then they would share that experience with the group.

I loved it. I thought it was amazing watching the women open up and how different they were from the beginning to the end. They shared their experiences and the changes they need to make internally. It was amazing.

One of the handlers with correctional experience spoke specifically about the impact of including animals in programs and how they enhanced her experience, as well as the experience of the population she was serving:

It's brilliant. There are so many programs at the jail and they receive so many certificates, which I see when I meet with my clients. But the ones that had animals, which are far and few in between, they can tell me all about. The other ones, they can't. This tells me that programs with animals are engaging and they remember the information. They can think back on them for another reason (the experience with the animal) and remember a skill they learned. It gives them the ability to connect this experience to other situations in life. They learn patience and how to be calm and how to care for another.

Two other handlers also spoke about the benefits of working with dogs in programs like PPP:

I enjoyed it. It was nice to see how quickly the women opened up with the dogs there. They got a lot out of the class [My dog] brought brightness to a place that was not a very bright spot in their future.

It has been an enriching experience personally and professionally to go through this program. It has brought me closer to [my dog] to have shared this with him. It is a very intimate program to deal with something so precious, like their children, and they are grieving and dealing with loss on so many levels. It was inspiring. Having him there just added to it and he added to their experience and made it special.

Overall, teams were very encouraged by the support of the jail:

I am very impressed. I am impressed by [the director] and the support the jail has given. I can equate this to when we go into a school. If we don't have buy in from the staff, it doesn't work. A lot of the success of a program, as with the women, is the professionalism. It comes across as warm and very relatable to the women but also professional. So, they feel valued and I think that makes them feel good.

\section{Discussion}

This exploratory research demonstrates that although there is much planning, preparation, and training needed when integrating dogs into therapeutic interventions, particularly in a correctional setting, they can be integrated safely and effectively. The procedures used by the individual therapy dog organizations in this study should serve to inform best practices and begin to lay the foundation for national standards, which are noticeably absent.

Four themes emerged from the data. First, all handlers felt that humans and nonhuman animals shared a very special bond. Responses indicated that all handlers possessed a strong commitment to PPP and the program participants. Handlers became involved in AAT because they recognized the mutually beneficial relationships that existed between humans and canines, and they also understood the vast benefits that AAT provided for 
human participants (Dunlap 2010; Esposito et al. 2011; Geist 2011; Kelly and Cozzolino 2015; Morrison 2007). The handlers found PPP to be a wonderful opportunity to work with a population they could not work with previously. Handlers believed their dogs had the right temperament for therapy work and could easily recognize the signs that their dog was enjoying their work. Teams were also aware that their dogs might like therapy work but did not necessarily like working with all populations. Some dogs did not enjoy working with children or in nursing facilities; all dogs enjoyed their work at the jail.

Second, handlers were confident in recognizing signs of stress in their canine partners and were knowledgeable in handling stressful encounters. The safety of their canine partner was a major concern, and all handlers appeared well trained in recognizing the signs of stress, which is an important component of AAT ethics (Evans and Gray 2012). Teams also knew how to handle the signs of stress in their canine; they appeared appropriately prepared by their therapy dog organization. On average, handlers would only commit to the recommended three visits per week (Iannuzzi and Rowan 1991). Most teams did not, however, recognize or identify this as part of ethics training. Simply asking handlers if they received ethics training is not enough, without further probing, to determine if they have or have not received it.

Third, there were differences between agencies in qualifying teams and requalifying teams annually, demonstrating inconsistencies within the field. Some handlers were more knowledgeable than others about worrisome behaviors in their canine partner, yet all appeared committed to their canine partner's safety and wellbeing. Testing is typically conducted with the canine partner; the human partner is not formally assessed on levels of knowledge. Therefore, it is difficult to know if handlers have retained a majority of the information provided during training sessions. Many therapy dog organizations will often "shadow" new teams on their first few therapy visits to evaluate how the human and non-human animal work together in a real-world setting. The evaluator can assess if the handler is able to apply what they learned in the training while visiting with clients. Yearly qualification, however, does not require a supervised visit. For the first few years of PPP, the Director of Training for PPP's community partner was onsite for all classes at the jails to safeguard against subjective assessment of canine behavior by the handler. In a stressful environment like a correctional setting, additional safeguards can help mitigate or prevent potential issues for the non-human animal. With a lack of national standards creating discrepancies in ethical training, certification/registration, recertification/requalifying, and practice for therapy teams (Pearson 2015; Winkle et al. 2020), these two AAT organizations have well-established best practices that will ensure therapy dogs are being included in therapeutic interventions properly and safely. It is important that mental health disciplines incorporate AAT in their ethical standards, where the greatest concern for canine safety may be the inclusion of dogs in private settings where handlers are not properly trained, and canines do not have to undergo any requalifying process to determine their continued suitability for this work (Pearson 2015).

Last, ensuring the wellbeing of a canine partner and their enjoyment of work in a correctional setting is highly feasible. Protocols created for PPP help establish guidelines for best practices and ethical integration of AAT in the correctional setting. None of the teams expressed long-term concerns for their dog's safety in the jail setting. Initial fears of working in an unknown environment were alleviated after the first visit. Concerns such as food on the floor and elevator use, among others, were easily rectified as long as they were reported to the director. Handlers, as a best practice, should make sure any concerns are reported immediately to their director. Study participants reported that once the PPP program director was made aware of a concern, she was easily able to address it with facility staff. Other than the issue of unpredictable noise, all other issues were rectified before the team's next visit. Clearly, good working relationships with correctional staff is a necessity. Without it, programming can be difficult. To maintain good relationships, all staff and residents should be informed about a dog's presence (Allen and Colbert 
2016); if anyone is fearful, steps should be taken to minimize contact between the dog and that person.

In order to make sure a canine is appropriate for the correctional setting, handlers and their dogs should have the opportunity to visit the facility before the start of the program for canine stress and suitability to be assessed. This should help to minizine the stress of the handler as initial safety concerns can be alleviated, especially since the stress level of the handler can inadvertently impact the stress level of their canine partner (Silas et al. 2019). Pre-program visits were added to the PPP protocol (when three new teams were hired) in the program's fourth year due to an incident that occurred during PPP's second year which required a team's removal from the program. The dog in the team exhibited clear signs of stress during his first two visits to the program. During the third visit, the dog's behavior became lethargic, and the director discovered that his handler was sedating the dog. The handler's willingness to compromise her dog's health in order to participate in the program underscores the need for established ethical standards for AAT programs. Therapy dog programs need to be mindful that although handlers may go through extensive training, their categorization of their dog's behavior is subjective and, as witnessed in this case, could result in transference, where projected feelings are related to their own self-interest (Hatch 2007; Milani 2016). Furthermore, private practitioners without affiliation to a therapy dog organization with established ethical standards can be problematic in that they may be forcing their dog to participate in a therapeutic intervention that is not safe or healthy for their canine partners.

Protocols should be put into place to minimize any risk to therapy dogs while entering or walking through the facility. Potential clients should also be vetted for problematic behaviors, such as violent outbursts, to minimize risk for working dogs. One handler also recommended including the dogs more in the group's community rules. In the first PPP class, the group discusses community rules (i.e., maintaining confidentially, remaining non-judgmental, etc.). All participants sign them to acknowledge their agreement. Even though PPP addresses the dog's safety in these rules (i.e., how to touch them, engage with them, etc.), future PPP cohorts, based on the recommendation of one of the teams, will also be taught to recognize signs of stress to serve as another layer of protection for the therapy dogs.

Teams acknowledged that jail visits could differ from traditional visits because of security protocols, the length of visit, and being more cognizant about dress, approved items to bring into the jail, and the sharing of personal information. Extensive training by both correctional staff and the host organization adequately prepared teams to work competently in this setting. The length of the visit for PPP is much longer than a typical therapy visit - two and a half hours compared to one hour (two hours for class and thirty minutes for processing). In some cases, the time spent in the jail was three hours if there were delays with coming or leaving. Although one hour is the recommended time for a therapy visit (Iannuzzi and Rowan 1991), PPP's structure allows dogs to take multiple breaks during the two-hour sessions where they can have a reprieve from residents to rest. During periods of instruction, where women were being taught new concepts, dogs would lay down, relax and sometimes sleep for an average of $20 \mathrm{~min}$. Once the group would become mobile again (i.e., participating in an activity or breaking into smaller groups), the therapy dogs were up, moving, and engaged. If visits need to be longer in special types of settings, like a jail, ensuring that dogs have access to water and frequent breaks will help to reduce any unnecessary stress (Allen and Colbert 2016).

Minor stress, which can occur in an unpredictable environment like a jail, can be lessened when handlers are trained appropriately and are knowledgeable enough to instruct clients correctly on how to engage with their therapy partner (Barstad 2014; Ng et al. 2014). The safety protocols of PPP helped to maintain a safe environment for the therapy dogs. As reported, the dogs enjoyed their visits to the jail, and none exhibited signs of stress. Most importantly, their behavior did not differ from therapy visits in other 
less restrictive settings. After the visits, dogs did not suffer from overfatigue or decreased motivation on future visits; both would signify signs of stress (Barstad 2014).

\subsection{Limitations and Future Research}

This research is exploratory and examines the experience of 11 teams who worked for a particular jail-based AAT program. These results provide a preliminary, albeit not exhaustive, account of working in a correctional institution with a canine partner. Due to the small sample size and the limitation of profiling two facilities, more research needs to be conducted to determine whether these results can be generalizable to other therapy teams in other correctional settings. Future researchers may also want to assess therapy dogs to see if there are behavior changes in programs greater in length than the one studied.

\subsection{Implications}

Implications suggest that canine partners can be included safely in a correctional environment, but there is an urgent need to create national guidelines from a governing body to ensure consistency in canine safety and enhance therapy-team professionalism in all settings. Although visits in the jail may be longer, visits can be safe when breaks are embedded into each session (Iannuzzi and Rowan 1991). Based on lessons learned from PPP, it is recommended that teams be allowed to visit the facility prior to the beginning of classes to see how the dog and handler manage in a correctional environment. Even with extensive training, it is difficult to know if a team can handle the demands of a jail setting; handlers cannot test for adaptability to this environment without being in the actual environment.

If cortisol levels are heightened on visit days, several days of rest may be needed following a visit to minimize further stress (Haubenhofer and Kirchengast 2006, 2007). When visiting a new environment, dogs need time to acclimate and should have the ability to leave or withdraw to a safe space if they are faced with a negative interaction (Glenk 2017). If dogs are working for longer periods in an institutional setting, they need mandated periods of rest and must have the ability to withdraw to a safe space, free from residents (Iannuzzi and Rowan 1991).

National standards on the inclusion of animals in the therapeutic process are needed, in addition to consistent training, certification and recertification standards. Animal therapy organizations typically have their own standards, but standards can vary greatly between organizations on methods of team selection, screening, training, evaluation, and recertification (Serpell et al. 2000). Dogs can be registered through AAT nonprofits, but the absence of national standards creates inconsistencies (Eccles 2020). One survey of AAT organizations found that approximately half did not have time limits for visitations (Serpell et al. 2000), even though it is recommended by researchers that visits only last one hour (Iannuzzi and Rowan 1991). The survey found a lack of consensus on the types of vaccinations required, whether food-based reward training was appropriate, if the use of aversive training methods was barred, whether raw meat diets should be prohibited to minimize the risk of transmission for zoonotic disease, or which mandates should be required for physical appearance (i.e., frequency of clipped nails, baths, flea and tick prevention, etc.). The survey also revealed differences with handler requirements and whether they should be over 18 and have to submit to a criminal background check, specifically whether they obtained child abuse history clearance. Handlers need formalized training; not only should handlers be able to recognize signs of stress and know how to respond, but they need to be able to instruct others how to properly interact with their canine partner (Glenk 2017); good interpersonal skills are essential.

In addition, mental health disciplines should add a section to their ethical standards relating specifically to the inclusion of all animals in therapeutic interventions. Animals should not be included without guidelines that protect their interests (Taylor et al. 2016). Although the American Psychological Association (APA) addresses the issue of animals in research, there are no specific standards, guidelines, or ethical principles in their code of 
ethics related to the integration of animals in therapy work (APA 2010; Eccles 2020). The integration of therapy animals is also absent from the ethical standards of the National Association of Social Workers (NASW 2017), the American Mental Health Counselors Association (AMHCA 2020), and the American Counseling Association (Stewart and Chang 2013). This is concerning for a variety of reasons. Most importantly, how many private practitioners incorporate dogs into treatment without proper training or oversight? Although private practitioners may obtain initial approval from a therapy dog organization, they do not requalify yearly because they are not volunteering with the respective therapy dog organization. Established guidelines from a governing body would assist in creating ethical practices that assist in the proper treatment and planning of AAT without causing harm to the canine or the client (Eccles 2020). As a copartner in therapeutic interventions, their safety is important and deserves a place within the ethical standards of mental health disciplines in order to abide by the 'do no harm' principle (Wollheim 2014). Professionals who are evaluated by a volunteer therapy dog organization may not have the same requirements or practices for human-canine teams that would be expected in a therapy setting. Standards enacted by therapy dog organizations, such as the two agencies profiled in this research, can be used to begin a conversation about national requirements to increase the professionalism of all humans who incorporate AAT in their work.

Author Contributions: Conceptualization, K.C.-C. and G.J.D.; methodology, K.C.-C. and G.J.D.; software, K.C.-C. and G.J.D.; validation, K.C.-C. and G.J.D.; formal analysis; K.C.-C. and G.J.D.; investigation, K.C.-C.; resources, K.C.-C. and G.J.D.; data curation, K.C.-C. and G.J.D.; writing-original draft preparation, K.C.-C.; writing-review and editing, K.C.-C. and G.J.D.; visualization, K.C.-C. and G.J.D.; supervision, K.C.-C. and G.J.D.; project administration, K.C.-C.; funding acquisition, K.C.-C. and G.J.D. All authors have read and agreed to the published version of the manuscript.

Funding: This research received no external funding.

Institutional Review Board Statement: The study was conducted according to the guidelines of the Declaration of Helsinki, and approved by the Institutional Review Board of Pace University (IRBNet ID No. 1737116-2; Approved on 7 May 2021).

Informed Consent Statement: Informed consent was obtained from all subjects involved in the study.

Acknowledgments: The authors would like to thank the Westchester County Department of Correction and the Metropolitan Correctional Center for their partnership, support and commitment to rehabilitative programming. A very special thanks to Hudson Valley Paws For A cause and the Good Dog Foundation for their partnership, support, and commitment to human and canine wellbeing. We would also like to thank the therapy teams who volunteer their time for this program, as well as our mothers and the Pace University students who make this program possible.

Conflicts of Interest: The authors declare no conflict of interest.

\section{References}

Allen, Kirsten, and Lindsey Colbert. 2016. Ethical and safety considerations for use of animals in a therapeutic setting. Psychotherapy Bulletin 51: 35-45.

American Mental Health Counselors Association (AMHCA). 2020. AMACHA Code of Ethics. Available online: https://www.amhca.org/ HigherLogic/System/DownloadDocumentFile.ashx?DocumentFileKey=24a27502-196e-b763-ff57-490a12f7edb1\&forceDialog=0 (accessed on 8 November 2021).

American Psychological Association (APA). 2010. Ethical Principles of Psychologists and Code of Conduct. Available online: https: / / www.apa.org/ethics/code (accessed on 8 November 2021).

Barstad, Borghild Njærheim. 2014. Evaluation of Animal Welfare in Dogs Working with Animal Assisted Interventions for Elderly People with Dementia. Master's thesis, Norwegian University of Life Sciences, Ås, Norway. Unpublished.

Brazier, Anna. 2014. Creature comfort? Animal assistance in therapeutic work with children and young people. Clinical Child Psychology and Psychiatry 19: 165-68. [CrossRef] [PubMed]

Chandler, Cynthia. 2001. Animal-assisted therapy in counseling and school settings. ERIC Digest. Available online: http://files.eric.ed. gov / fulltext/ED459404.pdf (accessed on 8 November 2021).

Collica-Cox, Kimberly, and Gennifer Furst. 2019. Parenting from a county jail: Parenting from beyond the bars. Issues in Mental Health Nursing 40: 593-604. [CrossRef] [PubMed] 
Collica-Cox, Kimberly, and George J. Day. Forthcoming. When dogs make the difference: Jail-based parenting with \& without animal-assisted therapy. Criminal Justice Policy Review.

Cooke, Barbara J., and David P. Farrington. 2015. The effects of dog-training programs: Experiences of incarcerated females. Women $\mathcal{E}$ Criminal Justice 25: 201-14. [CrossRef]

d'Angelo, Danilo, Serenella d'Ingeo, Francesca Ciani, Michele Visone, Luigi Sacchettino, Luigi Avallone, and Angelo Quaranta. 2021. Cortisol levels of shelter dogs in animal assisted interventions in prison: An exploratory study. Animals 11: 345. [CrossRef]

Dunlap, Vicki Marcelini. 2010. Canine Assisted Therapy and Remediating Reading: A Review of Literature. Master's thesis, Northern Michigan University, Marquette, MI, USA. Available online: https:/ / www.nmu.edu/sites/DrupalEducation/files/UserFiles/ Files/Pre-Drupal/SiteSections/Students/GradPapers/EdSpecialist/Dunlap_Vicki_EP.pdf (accessed on 8 November 2021).

Eccles, Emily P. 2020. Ethical Guidelines for Working with Animals in Clinical Settings (Publication No. 27741814). Doctoral dissertation, Fielding University, Santa Barbara, CA, USA.

Eddy, J. Mark, Charles R. Martinez Jr., and Bert Burraston. 2013. A randomized controlled trial of a parent management training program for incarcerated parents: Proximal impacts. Monographs of the Society for Research in Child Development 78: 75-93. [CrossRef]

Esposito, Layla, Sandra McCune, James A. Griffin, and Valerie Maholmes. 2011. Directions in human-animal interaction research: Child development, health, and therapeutic Interventions. Child Development Perspectives 5: 205-11. [CrossRef]

Evans, Nikki, and Claire Gray. 2012. The practice and ethics of animal-assisted therapy with children and young people: Is it enough that we don't eat our co-workers? The British Journal of Social Work 42: 600-17. [CrossRef]

Flynn, Erin, Katie Massey Combs, Jaci Gandenberger, Philip Tedeschi, and Kevin N. Morris. 2020. Measuring the psychological impacts of prison-based dog training programs and in-prison outcomes for inmates. The Prison Journal 100: 224-39. [CrossRef]

Geist, Traci S. 2011. Conceptual framework for animal assisted therapy. Child and Adolescent Social Work Journal 28: 243-56. [CrossRef]

Glaser, Barney G., and Anselm. L. Strauss. 1967. The Discovery of Grounded Theory: Strategies for Qualitative Research. London: Aldine Publishing Company.

Glenk, Lisa M. 2017. Current perspectives on therapy dog welfare in animal-assisted interventions. Animals 7: 7. [CrossRef] [PubMed]

Glenk, Lisa M., Oswald D. Kothgassner, Birgit U. Stetina, Rupert Palme, Berthold Kepplinger, and Halina Baran. 2013. Therapy dogs' salivary cortisol levels vary during animal-assisted interventions. Animal Welfare 22: 369-78. [CrossRef]

Glenk, Lisa M., Oswald D. Kothgassner, Birgit U. Stetina, Rupert Palme, Berthold Kepplinger, and Halina Baran. 2014. Salivary cortisol and behavior in therapy dogs during animal-assisted interventions: A pilot study. Journal of Veterinary Behavior 9: 98-106. [CrossRef]

Gorman, Richard. 2019. What's in it for the animals? Symbiotically considering 'therapeutic' human-animal relations within spaces and practices of care farming. Medical Humanities 45: 313-25. [CrossRef]

Granger, Ben, and Lori Kogan. 2000. Animal-assisted therapy in specialized settings. In Handbook on Animal-Assisted Therapy: Theoretical Foundations and Guidelines for Practice. Edited by Aubrey Fine. Cambridge: Academic Press, pp. 213-34.

Hatch, Alison. 2007. The view from all fours: A look at an animal-assisted activity program from the animals' perspective. ANTHROZOÖS 20: 37-50. [CrossRef]

Haubenhofer, Dorit K., and Sylvia Kirchengast. 2006. Physiological arousal for companion dogs working with their owners in animal-assisted activities and animal-assisted therapy. Journal of Applied Animal Welfare 9: 165-72. [CrossRef]

Haubenhofer, Dorit K., and Sylvia Kirchengast. 2007. Dog handlers' and dogs' emotional and cortisol secretion responses associated with animal-assisted therapy sessions. Animals \& Society 15: 127-50. [CrossRef]

Hollman, Leigh F., Shelly Wilkerson, Frances Ellmo, and Michael Skirius. 2020. Impact of animal assisted therapy on anxiety levels among mentally ill female inmates. Journal of Creativity in Mental Health 15: 428-42. [CrossRef]

Iannuzzi, Dorothea, and Andrew Rowan. 1991. Ethical issues in animal-assisted therapy programs. Anthrozoös 4: 154-63. [CrossRef]

International Association of Human-Animal Interaction Organizations (IAHAIO). 2018. The IAHAIO Definitions for Animal Assisted Intervention and Guidelines for Wellness of Animals Involved in AAI. International Association of Human-Animal Interaction Organizations: Available online: https:/ /iahaio.org/wp/wp-content/uploads/2017/05/iahaio-white-paper-final-nov-24-201 4.pdf (accessed on 8 November 2021).

Jasperson, Rachael A. 2010. Animal-assisted therapy with female inmates with mental illness: A case example from a pilot program. Journal of Offender Rehabilitation 49: 417-33. [CrossRef]

Kelly, Melissa A., and Callandre A. Cozzolino. 2015. Helping at-risk youth overcome trauma and substance abuse through animalassisted therapy. Contemporary Justice Review 18: 421-34. [CrossRef]

King, Camille, Jason Watters, and Sue Mungre. 2011. Effect of a time-out session with working animal-assisted therapy dogs. Journal of Veterinary Behavior 6: 232-38. [CrossRef]

Koda, Naoka, Yoshio Miyaji, Miyako Kuniyoshi, Yasumori Adachi, Gen Watababe, Chiemi Miyaji, and Kohei Yamada. 2015. Effects of a dog-assisted program in a Japanese prison. Asian Criminology 10: 193-208. [CrossRef]

Kunz-Lomelin, Alan, and Anne Nordberg. 2020. Assessing the impact of an animal-assisted intervention for jail inmates. Journal of Offender Rehabilitation 59: 65-80. [CrossRef]

MacNamara, Maureen, Jeannine Moga, and Christopher Pachel. 2015. What's love got to do with it? Selecting animals for animalassisted mental health interventions. In Handbook on Animal-Assisted Therapy: Foundations and Guidelines for Animal-Assisted Interventions, 4th ed. Edited by Aubrey G. Fine. Cambridge: Academic Press, pp. 91-101. 
Marinelli, Lieta, Simona Normando, C. Siliprandi, Martina Salvadoretti, and Paola Mongillo. 2009. Dog assisted interventions in a specialized centre and potential concerns for animal welfare. Veterinary Resource Communications 33: 93-95. [CrossRef]

McClanahan, Kimberly K. 2014. Can confidentiality be maintained in group therapy? The National Psychologist. Available online: http:/ / nationalpsychologist.com/2014/07/can-confidentiality-be-maintained-in-group-therapy/102566.html (accessed on 8 November 2021).

Milani, Myrna. 2016. Animal welfare in human-animal interactions. HABRI Central Briefs, 1-10. Available online: https://habricentral. org/resources/55219/download/hc_brief_welfare_and_hai20160208access002.pdf (accessed on 8 November 2021).

Miles, Matthew B., and A. Michael Huberman. 1994. Qualitative Data Analysis: An Expanded Sources Book, 2nd ed. Thousand Oaks: Sage.

Morrison, Michele L. 2007. Health benefits of animal-assisted interventions. Complementary Health Practice Review 12: 51-62. [CrossRef]

National Association of Social Workers (NASW). 2017. Code of Ethics. Available online: https://www.socialworkers.org/About/ Ethics /Code-of-Ethics / Code-of-Ethics-English (accessed on 8 November 2021).

Ng, Zenithson Y., Bess J. Pierce, Cynthia M. Otto, Virginia A. Buechner-Maxwell, Carlo Siracusa, and Stephen R. Werre. 2014. The effect of dog-human interaction on cortisol and behavior in registered animal-assisted activity dogs. Applied Animal Behavior Science 159: 69-81. [CrossRef]

Ng, Zenithson, Julie Albright, Aubrey H. Fine, and Jose Peralta. 2015. Our ethical and moral responsibility: Ensuring the welfare of therapy animals. In Handbook on Animal-Assisted Therapy: Foundations and Guidelines for Animal-Assisted Interventions, 4th ed. Edited by Aubrey. G. Fine. Amsterdam: Elsevier, pp. 91-101.

Nimer, Janelle, and Brad Lundahl. 2007. Animal-assisted therapy: A meta-analysis. Anthrozoos 20: 225-38. [CrossRef]

Palestrini, Clara, Valeria Calcaterra, Simona Cannas, Zita Talamonti, Fancesca Papotti, Debra Buttram, and Gloria Pelizzo. 2017. Stress level evaluation in a dog during animal-assisted therapy in pediatric surgery. Journal of Veterinary Behavior 17: 44-49. [CrossRef]

Parenting Inside Out (PIO). n.d. Outcome study. Parenting Inside-Out. Available online: http://www.parentinginsideout.org/ outcome-study/ (accessed on 8 November 2021).

Pearson, Jennifer. 2015. Ethical and Welfare Considerations for Animals in Therapeutic Settings. [Power Point Slides]. Graduate School of Social Work, University of Denver. Available online: http://www.denverpetpartners.org/wp-content/uploads/2016/01/ jpearsondpppresentation6-2015.pdf (accessed on 8 November 2021).

Pet Partners. n.d. Terminology. Available online: https://petpartners.org/learn/terminology/ (accessed on 8 November 2021).

Seivert, Nicholas P., Annmarie Cano, Rita J. Casey, Amy Johnson, and Dana K. May. 2018. Animal assisted therapy for incarcerated youth: A randomized controlled trial. Applied Developmental Science 22: 139-53. [CrossRef]

Serpell, James A., Katherine A. Kruger, Lisa M. Freeman, James A. Griffin, and Zenthinson Y. Ng. 2000. Current standards and practices within the therapy dog industry: Results of a representative survey of United States therapy dog organizations. Frontier Veterinary Science 7: 1-12. [CrossRef] [PubMed]

Shelton, Leslie S., Michael Leeman, and Caroline O'Hara. 2011. Introduction to Animal Assisted Therapy in Counseling. Available online: https:/ / www.counseling.org/resources/library/vistas/2011-v-online/Article_55.pdf (accessed on 8 November 2021).

Silas, Haley J., John T. Binfet, and Adam T. Ford. 2019. Therapeutic for all? Observational assessments of therapy canine stress in an on-campus stress-reduction program. Journal of Veterinary Behavior 32: 6-13. [CrossRef]

Silcox, Denise, Yuleinys A. Castillo, and Bruce J. Reed. 2014. The human animal bond: Applications for rehabilitation professionals. Journal of Applied Rehabilitation Counseling Volume 45: 27-37. [CrossRef]

Stetina, Birgit U., Christine Krouzecky, Lisa Emmett, Armin Klaps, Nora Ruck, Zuzana Kovaovsky, Anastasiya Bunina, and Jan Aden. 2020. Differences between female and male inmates in Animal Assisted Therapy (AAT) in Austria: Do we need treatment programs specific to the needs of females in AAT? Animals 10: 244. [CrossRef]

Stewart, Leslie, and Catherine Y. Chang. 2013. Animal Assisted Therapy in Counseling. ACA: Practice Briefs. The Center for Counseling Practice, Policy, and Research. Available online: https://www.researchgate.net/publication/324418718_Animal_ assisted_therapy_in_counseling_ACA_Practice_Briefs (accessed on 8 November 2021).

Taylor, Nik, Heather Fraser, Tania Signal, and Kathy Prentice. 2016. Social work, animal-assisted therapies and ethical considerations: A programme example from Central Queensland, Australia. British Journal of Social Work 46: 135-52. [CrossRef]

VanFleet, Rise, Aubrey H. Fine, Dana O'Callaghan, Teal Mackintosh, and Julia Gimero. 2015. Application of animal-assisted interventions in professional settings: An overview of Alternatives. In Handbook on Animal-Assisted Therapy: Foundations and Guidelines for Animal-Assisted Interventions, 4th ed. Edited by Aubrey G. Fine. Amsterdam: Elsevier, pp. 91-101.

Winkle, Melissa, Amy Johnson, and Daniel Mills. 2020. Dog welfare, wellbeing and behavior: Considerations for selection, evaluation and suitability for animal-assisted therapy. Animals 10: 2188. [CrossRef] [PubMed]

Wollheim, Peter. 2014. The case for animal-protective counseling practice. Counseling Today. Available online: https://ct.counseling. org/2014/10/the-case-for-animal-protective-counseling-practice/ (accessed on 8 November 2021).

Wycoff, Kirby L. 2014. Ethical considerations in animal assisted therapy. Elemental Animal Inc. Available online: https:// suzanneclothier.com/pdfs/WYCOFF\%20Ethical\%20Considerations\%20in\%20AAT.pdf (accessed on 8 November 2021).

Zamir, Tzachi. 2006. The moral basis of animal-assisted therapy. Society E Animals 14: 179-99. [CrossRef]

Zilcha-Mano, Sigal, Mario Mikulincer, and Phillip R. Shaver. 2011. Pet in the therapy room: An attachment perspective on AnimalAssisted Therapy. Attachment \& Human Development 13: 541-61. [CrossRef] 